\title{
UNA DIPLOMACIA A PALOS DE CIEGO
}

\author{
Ricardo Sánchez Ángel*
}

Universidad Libre de Colombia

DOI: http://dx.doi.org/10.14718/CulturaLatinoam.2019.30.2.13

\section{I}

El libro de Graziano Palamara sobre las relaciones de Italia con Colombia y Venezuela en la primera década de existencia de la Guerra Fría (1948-1958) constituye un aporte significativo a la historia comparada de las relaciones internacionales. El libro contiene, además de la introducción, un capítulo dedicado a la diplomacia italiana con América Latina durante el período del fascismo y, en particular, durante la Segunda Guerra Mundial. Allí se expone la trama de las movidas y vicisitudes del inevitable proceso de aislamiento y repudio por parte de América Latina a Italia, al igual que el tejido del hilo conductor de esas relaciones en el contexto de la derrota italiana y la aceptación de la misma frente a las potencias vencedoras: Estados Unidos e Inglaterra. Un segundo capítulo, con el título "El difícil retorno de Italia en América Latina”, retrata la saga italiana por la reconstrucción de su presencia en nuestra América. Ambos capítulos

\footnotetext{
* Doctor en Historia (Universidad Nacional de Colombia). Fue decano de la Facultad de Derecho de la Universidad Nacional de Colombia y director del Instituto para el Desarrollo de la Democracia Luis Carlos Galán. Autor de varios libros y artículos. Contacto: rsangel49@gmail. com
} 
fijan un contexto histórico que permite precisar las maneras como se fue presentando el cambio hacia el aislamiento y la derrota de Italia, junto con la ruptura e incluso declaración de guerra por parte de la mayoría de los países latinoamericanos. Así las cosas, el período analizado meticulosamente, y con sorprendente pericia investigativa, de las dictaduras de Pérez Jiménez y Rojas Pinilla no comienza en 1948 sino desde los inicios del gobierno de Benito Mussolini.

Se destacan en este trabajo las fuentes de archivos de las relaciones diplomáticas en Italia, principalmente, el cuidadoso relato historiográfico de autores italianos, venezolanos y colombianos y un acertado método de interrelación de espacios, períodos y contextos económicos, culturales, y especialmente diplomáticos, ubicando la situación concreta de cada uno de los tres países. En verdad cuatro, incluyendo a Estados Unidos. Son relaciones en carambola de cuatro bandas, con la primacía de los ganadores de la Segunda Guerra Mundial.

Lo que hace el historiador Graziano Palamara es desplegar un análisis global sobre el discurrir de los procesos y situaciones concretas que se estudian. En ese sentido, el contexto de la Guerra Fría adquiere gran importancia, fue diseñado y operado por la presidencia de Truman poco después del lanzamiento de la bomba atómica sobre las ciudades japonesas de Nagasaki e Hiroshima. Es sobre estos hongos nucleares que se cierra el ciclo militar de la guerra y que se da inicio a la conformación de un estado de la seguridad nacional para garantizar sus intereses geopolíticos globales. La Guerra Fría fue la doctrina del disciplinamiento de Europa, Asia y América Latina, donde las intervenciones militares en Corea (1950-1953) y Guatemala (1954) señalaron que la expresión fría era un adjetivo, mientras la guerra el sustantivo.

Como lo recuerda Perry Anderson (2014) en su libro sobre la política internacional de Estados Unidos, lo que acompañó a la doctrina de la seguridad nacional era la democracia, el mundo libre como paradigma ideológico y la invocación a Dios como el protector de Estados Unidos en el cumplimiento de su tarea de combatir al comunismo como el mal a exterminar: "Enfrentarse a la amenaza soviética era más urgente que afinar la Pax Americana y hubo que aplazar algunos de los principios de esta paz para combatir el comunismo".

La preocupante afirmación de Winston Churchill de la caída de una cortina de hierro entre el mundo libre de Europa y la Unión Soviética adquirió su simbolismo en la construcción del Muro de Berlín (13 de agosto de 1961 - 9 de noviembre de 1989). La caída de este muro señaló el fin de la Guerra Fría, dada la inmensa crisis de dominación 
de la burocracia soviética en todo el orden de los países del socialismo realmente existente. No obstante, Estados Unidos mantuvo la promoción de la seguridad nacional como política exterior.

\section{II}

Italia fue derrotada en la Segunda Guerra Mundial. No solo el régimen fascista de Benito Mussolini, sino toda la península itálica, fue castigada. Los italianos no sufrieron los rigores extremos sufridos por Alemania, pero fueron ocupados y pasaron a ser un especie de protectorado norteamericano.

La política de Europa occidental, encabezada por Gran Bretaña, fue la del Atlantismo, una alianza en que los Estados Unidos aparecían como socio dominante, condición del Plan Marshall de reconstrucción europea. El Partido de la Democracia Cristiana encabezó el retorno a la democracia en Italia, con participación de comunistas, radicales y socialistas, bajo los parámetros establecidos en el nuevo orden de la Guerra Fría.

Es sobre esta realidad histórica que Italia relanzó su política internacional y, en especial, con América Latina. Palamara muestra a la diplomacia italiana moverse como gato entre porcelanas para evitar quebrar, en cualquier forma, los parámetros de Washington en lo que era su órbita de influencia: América Latina. Con finura analítica, se muestra cómo operó este mecanismo, cómo se aplicó esta diplomacia.

Muy a pesar que el servicio exterior del gobierno italiano señaló como prioridad adelantar una política de recuperación y reconocimiento de América Latina, dada su importancia histórica y cultural, esto no sucedió. A juicio del autor, hubo mucha improvisación y falta de voluntad política para llevar a cabo esta tarea. Se exceptúan las destacadas gestiones de algunos diplomáticos italianos.

Esta situación está condicionada: de un lado, por el papel subordinado de Italia a Estados Unidos. De otro lado, se careció de una audaz estrategia por parte de Colombia y Venezuela, ya que su papel, igualmente subalterno, los mantuvo atentos, con ilusión, a las ofertas del comercio, la inversión de capitales de los Estados Unidos y a favorecerse del nuevo orden económico del Bretton Woods: el Fondo Monetario Internacional, el Banco Mundial y la supremacía del dólar.

Además, América Latina consiguió, con la Conferencia Panamericana de Bogotá y la fundación de la Organización de Estados Americanos (OEA), un campo de representación en la búsqueda de una 
colaboración subordinada con Estados Unidos. La conferencia la presidió el general George Marshall, jefe del Estado Mayor del Ejército norteamericano durante la Segunda Guerra Mundial y Secretario de Estado, de quien se tomó el nombre del plan de reconstrucción europeo, conocido también como European Recovery Program, ERP. La tutela de Estados Unidos se volvió más coherente en la búsqueda de la eficiencia del libre comercio y en la eficaz aplicación del propósito anticomunista de la Guerra Fría, que se formalizó en la X Conferencia Americana de 1954 en Caracas. Allí, el delegado principal de Estados Unidos, Foster Dulles, presionó votar una resolución anticomunista.

Esta política de la Guerra Fría para América Latina comenzó en 1947 con la firma del Tratado Interamericano de Asistencia Recíproca (TIAR) en Rio de Janeiro.

\section{III}

Al comenzar la liberación del fascismo, se buscó el apoyo latinoamericano para restablecer la condición de amistad con estas repúblicas. Con criterio realista, la diplomacia italiana vio la oportunidad de lograr el apoyo latinoamericano como bloque en las Naciones Unidas. Italia quería ser tratada como miembro pleno en el organismo, al igual que en el concierto internacional, invocando los lazos históricos con la cultura latina. Con generosidad, nuestra América apoyó activamente a Italia en sus pretensiones. No obstante, se firmó un acuerdo entre el canciller británico Bevin y el italiano Sforza el 6 de mayo de 1949, asumido por los latinoamericanos como una bofetada a sus gestiones y propuestas.

Italia tuvo que esperar hasta 1954 para ser aceptada en las Naciones Unidas. Pero, sin duda, con sus maniobras pervirtió el primado esencial de la diplomacia: la confianza. Procedió con pragmatismo oportunista, menoscabando los argumentos del derecho internacional que jugaban a su favor.

La posición italiana estuvo definida por el atlantismo y el europeísmo. Sus preferencias reales estaban en el mediterráneo, en las ex colonias africanas y, por supuesto, Estados Unidos y Europa. Italia no tenía un campo abierto para sus iniciativas, sino un estrecho callejón por donde transitar.

Desde entonces se dio un proceso que el autor denomina como el difícil retorno de Italia en América Latina. Un retorno que se dio dando palos de ciego, buscando la fuga ante la realidad de la políti- 
ca internacional: la de una Italia castigada por los vencedores, con la hegemonía de Estados Unidos. De la lectura de la erudita exposición del autor se puede concluir que la diplomacia italiana construyó una ficción sobre su papel en América Latina, con las formulaciones de la colaboración triangular: Italia, Estados Unidos y América Latina.

El éxito económico — tan reivindicado como "milagro" - y la adopción de una constitución democrática, facilitaron la unidad nacional y la promoción internacional de la Italia de la postguerra. En Nuestra América fueron de buen recibo estos logros, pero no tuvieron la fuerza para ser el imán que quería ejercer la diplomacia de Italia.

\section{IV}

La itálica famosa lo fue también en Nuestra América por la filiación con su cultura, en que el derecho romano fue el referente del civilismo jurídico. Los clásicos: Virgilio y su Eneida, Dante Alighieri y su Divina Comedia, Nicolás Maquiavelo con El Príncipe; Roma, incluyendo el Estado Vaticano; las ciudades-Estado, verdaderas obras de arte, como Florencia y Venecia; el Renacimiento, con sus grandes artistas como Miguel Ángel, Rafael y muchos otros. La Última Cena de Da Vinci era una estampa pegada a las paredes de hogares y tiendas. El latín, que se cultivó en las instituciones educativas nuestras hasta los años ochenta del siglo XX, tuvo afamados cultores como el presidente Miguel Antonio Caro, quien realizó una versión de La Eneida. El prestigio de los estudios de derecho en las universidades italianas hizo que personajes como Jorge Eliecer Gaitán estudiaran derecho penal con Enrico Ferri y fuera su alumno sobresaliente. En fin, una multitud de influencias simbólicas que arraigaron su presencia en Nuestra América.

Fue Italia la que nombró a Colombia, Venezuela y al continente con la filiación de su lengua. América tomó el nombre del gran navegante Américo Vespucio y Colombia hizo lo propio con el almirante Cristóbal Colón. Venezuela tiene su filiación con Venecia.

El recuerdo de Agustín Codazzi también es pertinente evocarlo, en tanto que, además de italiano, fue al mismo tiempo, de hecho, colombo-venezolano. Una personalidad fascinante, que la escritora Beatriz Caballero (1994) definió en un bello libro.

De la vida de Codazzi más que de la de nadie puede decirse que fue un viaje o mejor, 7 viajes: cada uno corresponde a una edad, a un lugar, a una faceta suya. La primera vida, como soldado de Napoleón; 
la segunda, de aventurero por Europa; la tercera, fue pirata en el Caribe; la cuarta, mercenario de la independencia americana; la quinta, granjero en Italia; la sexta, jefe militar y geógrafo de Venezuela; y la séptima, en la Nueva Granada con la Comisión Corográfica.

Codazzi, en sus facetas múltiples, fue el fundador del internacionalismo italiano en estos territorios. Así, en la crónica histórica de nuestra independencia, su figura resalta. Destaco que se erigió como un libertador, bajo el mando de Luís Aury, del Archipiélago de San Andrés, Providencia y Santa Catalina, con la bandera de la República argentina y chilena. También tuvo protagonismo científico, tanto en Colombia como en Venezuela, en la geografía y la cartografía. En su honor, el Instituto Geográfico de Colombia tomó su nombre. Con razón se le señala como un descubridor del Nuevo Mundo, al lado de Alejandro Humboldt, Elisee Reclus y otros exploradores. Con la unidad italiana, los Estados Unidos de Colombia reconocieron la monarquía de Víctor Manuel II.

El otro grande internacionalista fue nadie menos que Giuseppe Garibaldi (1807-1882), el héroe de la unidad italiana. Se exilio en Sudamérica, donde libró batallas contra el Imperio de Brasil y la Confederación de Argentina, defendiendo la soberanía uruguaya. Garibaldi viene a ser, con su Legión Italiana, la de "virtuosos saqueadores", como él la denominó, un personaje de leyenda. Su periplo americano es mucho más amplio, porque visita Nicaragua y se establece durante un tiempo luchando por ideales republicanos. También México y Estados Unidos. Como gran aventurero y corsario, Garibaldi visitó a la mítica libertadora Manuela Sáenz, la compañera de Simón Bolívar, en la localidad de Paita (Perú). El imaginario sobre Garibaldi no desapareció y ha sido un referente de idealismo revolucionario en Nuestra América. No en balde es reconocido como el héroe de dos mundos (Europa y América).

Ahora bien, tal como lo precisa Graziano Palamara, Italia presentó dos grandes diásporas producto de crisis sociodemográficas y políticoeconómicas. La primera va de 1870 a 1920 y la segunda comenzó en 1946 y duró hasta 1973. Emigraron 7 millones de italianos, de los cuales la mayoría vinieron a América Latina. La migración se convirtió en el motor sociocultural más importante de Italia en Nuestra América.

En Colombia, la migración italiana fue muy baja en contraste con Venezuela. Las autoridades y las reglamentaciones no propiciaron la política de la migración, desperdiciando las ventajas comparativas que obtuvo Venezuela. Argentina fue el mayor receptor de la diáspora italiana, seguido de Brasil y México. 
Tema especial lo constituye la relación entre Colombia y el Vaticano a partir de la firma en 1887 de un Concordato, producto de la contrarreforma de la Constitución autoritaria de 1886. Roma Locuta es la metáfora de la hegemonía católica sobre la vida política y cultural de los colombianos. Los conservadores dependían del visto bueno de Roma para las candidaturas presidenciales. Lo de un país católico, con una sola lengua - el castellano — y una sola raza — la blanca criolla- fue la impostura durante muchos años, que solo con la Constitución de 1991 se empezó a cambiar mediante la proclamación del Estado laico.

El Partido Liberal se declaró concordatario desde 1909, cuando los jefes liberales Benjamín Herrera, Lucas Caballero y Carmelo Arango firmaron, al lado de los jefes conservadores Miguel Abadía Méndez, Pedro Nel Ospina y Carlos E. Restrepo, un documento en que pidieron "conservar intactos los principios consignados en la Constitución de 1886 y en el Concordato vigente”.

Así las cosas, se dio un Estado semiteocrático, que cedió parte sustancial de su soberanía en educación, matrimonio y familia, la supremacía de la legislación canónica, el fuero eclesiástico, el carácter económico de la función religiosa, la educación y control de los pueblos indígenas. Esto, en el contexto de una expresa declaración del catolicismo como la religión oficial de los colombianos y a la cual el Estado debía su protección.

A la luz de lo señalado, el margen del Estado italiano para tener acogida en Colombia era mínimo. Tales relaciones las copaba el Vaticano. Entre tanto, las relaciones de Italia con Venezuela fueron más favorables, a tal punto que nuestro historiador recuerda el "hilo rojo" que desde Colón a Bolívar, pasando por los grupos migratorios del siglo XIX y XX, unió a Italia con Venezuela. Una de las claves está en que Venezuela no tuvo dependencia del Vaticano. Al contrario, permaneció vigente el Patronato Eclesiástico desde el Congreso de Cúcuta de 1824, que le daba prerrogativas al Estado sobre la Iglesia, hasta que fue aprobado el Convenio de modus vivendi entre la Iglesia y el Estado en 1964 (Campo del Pozo, 2017).

Sobre las dictaduras de Pérez Jiménez y Rojas Pinilla, el autor logra sendos escrutinios sobre los alcances y perfiles de esos regímenes. Los caracteriza como desarrollistas. Y, para el caso colombiano, como bonapartista, que me parece es extensible a Venezuela. Italia seguiría la línea trazada por Washington de reconocer los gobiernos de estos dos países. Este escrutinio constituye el eje central del libro. 
Un detalle que hace las delicias del lector es la costumbre italiana de condecorar los altos funcionarios del Estado. Se puede decir que se trató de una diplomacia de las condecoraciones. Desde entonces, paulatinamente las relaciones alcanzaron mayoría de edad hasta nuestros días.

\section{V}

Las relaciones de Italia con Colombia y Venezuela conocen tragicomedias que enrarecieron el ambiente diplomático. Es cuando la bota italiana decide intervenir militarmente con la diplomacia de los cañones en ambos países. Palamara resalta estos episodios y su repercusión negativa en las relaciones e imaginarios de nuestros pueblos frente a estas agresiones. La División Naval para América Latina fue creada para atender los contenciosos con nuestros países.

El suceso colombiano se conoce como la Cuestión Cerruti. En 1885 este personaje se comprometió en el apoyo a los federalistas del radicalismo liberal, fue detenido y sus bienes ocupados y saqueados. Cerruti fue un personaje de la mayor importancia, tal como lo destaca una de sus víctimas, el autor de La María, Jorge Isaacs, quien dirigió la revolución radical en Antioquia entre el 28 de enero y el 6 de marzo de 1880. Isaacs era un destacado político del liberalismo radical. Cerruti había fundado una casa comercial y financiera en sociedad con destacados personajes liberales - La casa de Cerruti y compañia- e intervino activamente en las luchas políticas de Cauca y Antioquia.

Rápidamente la Legación de Italia reclamó los derechos de Cerruti y su libertad. El crucero italiano Flaveo Goia atracó en Buenaventura, rescató al súbdito italiano, desembarcó tropas e hizo incursiones en distintas partes.

En julio de 1888 llegó a Cartagena una flota italiana, compuesta por cuatro naves de guerra: el Crucero Carlos Alberto, con 49 cañones; la fragata Bausán, con 25; la Calabria, con 20; y la Umbría, con 31. La tripulación estaba compuesta de 1378 hombres. El comandante de la flota era el Almirante Candiani, quien exigió que se cumpliera el fallo arbitral del presidente de Estados Unidos, Grover Cleveland, el cese de todo proceso contra Cerruti y sus empresas y pagarle el costo de sus bienes y daños con intereses. La flota italiana, por supuesto, no solo hizo maniobras amenazantes en la bahía, sino que desembarcó en Cartagena. El presidente Rafael Núñez, quien era cartagenero, 
fue impotente para defender los intereses de la soberanía nacional. No obstante, escribió un poema punitivo, "A Cartagena, cercada de bandidos" (1885). Al mismo tiempo, en Barranquilla, otro barco italiano se hizo presente para coadyuvar la exigencia de reconocer los intereses de Cerruti. Colombia rompió relaciones diplomáticas con Italia.

Además, avanzadas las gestiones para el pago a Italia, se puso de manifiesto el hecho de que el 11 de diciembre de 1898 se decidió que el crucero real Ettore Fieramosca zarpara hacia aguas de Colombia para resolver la cuestión Cerruti.

El Gobierno colombiano se vio obligado, hasta 1910, a pagar la totalidad de la deuda. La cuestión Cerruti duró más de 26 años y enredó las posibilidades de un entendimiento entre el país europeo y Colombia.

Venezuela también sufrió el intervencionismo italiano entre 1902 y 1903, durante el gobierno de Cipriano Castro. Bloquearon los puertos venezolanos en compañía de Alemania e Inglaterra para exigir la anulación de las deudas de sus súbditos y la compensación de estos por los daños sufridos en las guerras civiles.

\section{VI}

En una perspectiva de historia desde bajo, hay que rescatar el internacionalismo proletario de Vicente Adamo (1876 - ¿?), nacido en Reggio (Calabria - Italia). Este personaje se embarcó en Nápoles en 1900 rumbo a México, Cuba y Colón, trabajando en ingenios, casinos y ferrocarriles, hasta llegar a la región del Sinú, en Colombia, en 1915, donde ejerció distintos oficios, incluso en el matadero público de Montería. En la plaza de mercado montó su base proselitista de ideas socialistas y algo de anarquismo.

Pero Adamo no era solo un predicador laico de la doctrina socialista. También se distinguió como organizador de los artesanos, carpinteros, herreros, zapateros, talabarteros, en compañía de vendedores del mercado y trabajadores manuales. Luego se extendería la actividad entre los campesinos. La vanguardia fueron las mujeres, convocadas por Juana Julia Guzmán (1892-1975), tabacalera primero, luego trabajadora doméstica, cantinera y ventera barrial. Supo de las ideas que pregonaba Adamo, lo buscó y fue amor a primera vista hasta la expulsión de este de Colombia. Ella conservó su única fotografía conocida. 
Juana Julia tuvo una gran influencia sobre Vicente Adamo. Ella era una líder carismática, que organizó a las mujeres en Montería y logró la construcción de un Hospital Socialista, una escuela obrera y una biblioteca popular. A su vez, la tenacidad de Adamo influenció a su compañera de luchas, siendo este el promotor del Comité Socialista y la Sociedad de Obreros y Artesanos de Montería. Entre el 21 y el 27 de enero de 1921 se realizó la Asamblea de Campesinos y Obreros de la Costa Atlántica, donde se acordaron las bases del Partido Obrero. Escribe Orlando Fals Borda (1986): “(...) el impacto real del nuevo socialismo se siente primero en el Sinú que en Bogotá, con la llegada a Montería del obrero italiano Vicente Adamo en 1918, admirador de la reciente revolución rusa" (p. 146b).

En la lucha por la tierra, Vicente Adamo organizó a los campesinos parcelarios en cooperativas y fundó varios poblados, entre ellos El Baluarte Rojo, lugar de su residencia. Los terratenientes reaccionaron airadamente y la fuerza pública reprimió y asesinó a tres labriegos, al igual que al teniente al mando de la operación. Vicente Adamo, al igual que otros compañeros, estuvo recluido en Cartagena durante treinta meses.

En torno al preso político italiano y al líder indígena Manuel Quintín Lame se adelantó una campaña de solidaridad liderada por María Cano. Libres, Vicente y Juana Julia volvieron a sus andadas. Fundaron otra sociedad, pero solo de obreros de Montería y la represión se desató contra ellos. Vicente fue puesto preso de nuevo y expulsado del país en 1927, vía Curazao hasta Chicago. La Legación italiana en Bogotá facilitó el trámite de la expulsión de Adamoํ. Su rastro, dice Fals Borda, se perdió en un hospital en Ciudad Trujillo (República Dominicana).

El socialismo de Adamo era reformista en el programa y revolucionario en la acción. En eso consiste su grandeza internacionalista de la mano de Juana Julia.

\section{VII}

Lo que evidencia la saga histórica estudiada por Graziano Palamara es la supremacía de las relaciones internacionales hegemonizadas por los vencedores, en especial por los Estados Unidos, sobre el

1. Carta de la Legación Italiana al ministro de Relaciones Exteriores de Colombia, Antonio Gómez Restrepo, de diciembre 9 de 1926. El documento se encuentra en el Archivo General de la Nación (AGN), fondo Ministerio de Relaciones Exteriores, caja 599, carpeta 70, folio 192. 
derecho internacional y la diplomacia. Es necesario tener en cuenta la siguiente perspectiva.

A las ciudades-Estado italianas se les atribuyen los comienzos de la diplomacia occidental. Su papel no es solo el de buscar soluciones a conflictos, que son o pueden ser bélicos, sino buscar mejorar las relaciones, mantenerlas en un statu quo, o potenciarlas, al igual que se propone conseguir aliados de todo orden. El horizonte de la interrelación cultural, económica y comercial está en los propósitos de la diplomacia.

Los gobiernos mantuvieron relaciones entre sí en condiciones de igualdad o subordinación y sometimiento desde que aparecieron los Estados. Se hicieron a través de acuerdos, entendimientos y treguas. No existía la diplomacia estable, sino de enviados especiales: los embajadores.

El derecho internacional va a ser una racionalización del derecho natural, que propició la formalización de las relaciones entre los Estados, codificando experiencias y propósitos. Se establecieron normas de comportamiento, patrones de conducta, buscando estabilidad y confianza entre las partes. El resultado de las reglas del juego tuvo una particular jerarquización, al incluir la regla de oro del derecho a la guerra, que vino a ordenar el conjunto del derecho internacional. Es el primero de los derechos que los Estados reclaman como garantía de protección de sus intereses, no solo como derecho de defensa legítima, sino como forma de realización. Es el centrismo de los Estados nacionales con sus dinámicas de expansión. El derecho internacional fue no solo la formalización de las relaciones entre Estados, sino, también, el espacio del cosmopolitismo que propiciaron, entre otros, Rousseau y Kant, y que la Revolución Francesa impulsó como onda internacional hacia una ciudadanía en común. Así las cosas, las relaciones internacionales, el derecho y la diplomacia forman el sistema de Estados, bloques continentales e imperios, al igual que la presencia de los Estados subordinados, siendo estas relaciones contradictorias e incluso antagónicas.

La expresión más avanzada del cosmopolitismo es el sistema de las Naciones Unidas. Las formulaciones y prácticas de las grandes potencias, con sus respectivas elaboraciones teóricas, privilegian las relaciones internacionales en su visión pragmática y disciplinan a sus intereses el derecho internacional y la diplomacia.

En el complejo devenir del orden internacional, regido por la diada de paz y guerra, la diplomacia viene a ser la praxis necesaria para el mantenimiento de la paz, al igual que la búsqueda del logro de la 
misma. La diplomacia permite, mediante el diálogo y negociación con carácter profesional, respetar el derecho internacional y procurar la democratización del sistema de Naciones Unidas que, pese a la presencia abrumadora de todos los Estados, es manejada por las grandes potencias a través del Consejo de Seguridad.

No es casual que el teórico del realismo en las relaciones internacionales, Hans J. Morgenthau (1986), afirme la necesidad de una revitalización de la democracia, que tiene como premisa el reconocimiento pragmático del fracaso de la diplomacia muchas veces, pero también sus éxitos otras tantas.

El mundo de hoy, convulsionado, con un orden desordenado, con guerras y amenazas, podría ser peor sin una diplomacia con las herramientas del derecho internacional de la paz y en el marco de unas Naciones Unidas democratizadas. Las pesadillas de la barbarie y las guerras estarían instaladas en nuestras vidas de una manera más intensa.

\section{Referencias}

Arboleda, G. (1933). La reclamación de Cerruti. Boletín bistórico del Valle, (6), 244-264.

Caballero, B. (1994). Las siete vidas de Agustín Codazzi. Bogotá: Instituto Geográfico Agustín Codazzi - Carlos Valencia Editores.

Campo del Pozo, F. (2017). Convenio de la Santa Sede con el Estado venezolano en 1964. Montalbán: Revista de Humanidades y Educación, (49), 402-428.

Dumas, A. (1999). Memorias de Garibaldi. Madrid: Globus.

Fals, O. (1986). Historia doble de la costa. Bogotá: Universidad Nacional de Colombia - Carlos Valencia Editores.

Isaacs, J. (2009). Obras Completas. Bogotá: Universidad Externado de Colombia - Universidad del Valle.

Lemaitre, E. (1974). La bolsa o la vida. Cuatro agresiones imperialistas contra Colombia. Bogotá: Biblioteca del Centenario del Banco de la República.

Morgenthau, H. (1986). Política entre las naciones. La lucha por el poder y la paz. Buenos Aires: Grupo Editorial Latinoamericano.

Perry, A. (2014). Imperium et Consilium. La política exterior norteamericana y sus teóricos. Madrid: Akal. 
Tamburini, F. (2000). La cuestión Cerruti y la crisis diplomática entre Colombia e Italia (1885-1911). Revista de Indias, 9(220), 709733.

Valencia, A. (1988) “¡Centu per centu, moderata ganancia!”: Ernesto Cerruti, un comerciante italiano en el estado soberano del Cauca. Boletín Cultural y Bibliográfico, 25(17), 55-75. 